\title{
Trapping Pandemis limitata (Lepidoptera: Tortricidae) moths with mixtures of acetic acid, caterpillar-induced apple-leaf volatiles, and sex pheromone
}

\author{
Gary J.R. Judd, ${ }^{1}$ Alan L. Knight, Ashraf M. El-Sayed
}

\begin{abstract}
Pandemis limitata (Robinson) (Lepidoptera: Tortricidae) is one of several leaf-feeding caterpillar pests of commercial tree-fruit crops in British Columbia, Canada. Recent discovery that European Pandemis Hübner species are attracted by lures combining acetic acid and the caterpillar-induced apple-leaf volatiles, 2-phenylethanol, and phenylacetonitrile, prompted our examination of $P$. limitata response to these compounds. Trapping tests in organic apple orchards revealed that neither of these individual benzenoids, nor their binary combination, was attractive. Acetic acid alone was weakly attractive, but more importantly, catches increased significantly when an acetic-acid co-lure was combined with 2-phenylethanol or phenylacetonitrile, individually and together. Catches of male and female $P$. limitata with acetic acid +2-phenylethanol, or acetic acid +2-phenylethanol + phenylacetonitrile were similar, respectively, and both sexes were caught significantly less often in traps baited with acetic acid + phenylacetonitrile. When combined with acetic-acid co-lures, traps baited with membrane dispensers releasing 2-phenylethanol at $\sim 1 \mathrm{mg} /$ day caught significantly more moths than traps baited with rubber septa lures releasing 2-phenylethanol at $\sim 0.6 \mathrm{mg} / \mathrm{day}$. Moth catches in traps baited with 2-phenylethanol were unaffected when the emission of acetic-acid co-lures was increased from $\sim 28$ to $63 \mathrm{mg} / \mathrm{day}$. Catches of male $P$. limitata in traps baited with sex pheromone were significantly greater than catches in traps baited with acetic acid +2-phenylethanol, or traps baited with a ternary blend of acetic acid +2 -phenylethanol + sex pheromone. Catches of female $P$. limitata in traps baited with acetic acid +2-phenylethanol were significantly reduced when it was combined with sex pheromone. Use of the ternary acetic acid +2-phenylethanol + phenylacetonitrile blend provides an opportunity to develop multispecies bisexual trapping systems to improve management of sympatric tortricid pests currently causing economic losses in organic apples in British Columbia. More work on long-lasting release devices, nonsaturating traps, and organically acceptable killing agents are needed to develop organic mass-trapping systems.
\end{abstract}

\section{Introduction}

Several polyphagous leaf-feeding caterpillar species (Lepidoptera: Tortricidae) form an important pest complex in commercial plantings of apple, Malus domestica Borkhausen (Rosaceae), and pear, Pyrus communis (Linnaeus) (Rosaceae), in the Pacific Northwest of North America (Madsen and Procter 1985; Beers et al. 1993). Summer-generation larvae of bivoltine leafroller species like Pandemis limitata (Robinson), P. pyrusana Kearfott, and
Choristoneura rosaceana Harris are the most important species that damage apples when larvae construct leaf shelters and feed on adjacent fruits (Brunner and Beers 1990). Conventional apple producers usually manage these leafrollers with synthetic insecticides (Beers et al. 1993) but organic apple producers have few effective insecticides (Edwards 1998). Pheromone-based mating disruption is an established method for managing tortricid species (Witzgall et al. 2010). Some organic apple growers in the Pacific Northwest are using

Received 9 December 2016. Accepted 27 February 2017. First published online 6 September 2017.

G.J.R. Judd, ${ }^{\mathbf{1}}$ Agriculture and Agri-food Canada, Summerland Research and Development Centre, 4200 Highway 97, Summerland, British Columbia, Canada, V0H 1Z0

A.L. Knight, United States Department of Agriculture, Agricultural Research Service, 5230 Konnowac Pass Road, Wapato, Washington, 98951-9651, United States of America

A.M. El-Sayed, The New Zealand Institute for Plant and Food Research Limited, Gerald Street, Lincoln 7608, New Zealand

${ }^{1}$ Corresponding author (e-mail: Gary.Judd@agr.gc.ca)

Subject editor: Matt O'Neal

doi: $10.4039 /$ tce. 2017.38 
multispecies sex pheromone mating disruption to manage a complex of leafroller pests including Pandemis Hübner species (Knight et al. 1998; Knight and Turner 1999; Judd and Gardiner 2004, 2008).

The efficacy of these pheromone-disruption technologies can be threatened by high female moth density within orchards and the immigration of mated females from alternative host plants surrounding orchards (Cardé and Minks 1995). Our ability to easily measure these threats is limited, but experience with codling moth shows semiochemical-based monitoring of female moths can be helpful in this situation (Knight 2010; Hári et al. 2011). Monitoring female moth populations provides producers the information needed to apply supplemental controls when and where needed. Unfortunately, identified chemical attractants for female moths are rare among tortricid species (El-Sayed 2016). Nevertheless, recent research has shown that acetic acid in combination with some caterpillar-induced apple-leaf volatiles having a benzenoid structure can attract several tortricid species (El-Sayed et al. 2016; Giacomuzzi et al. 2016).

European studies have thoroughly characterised the volatiles released by apple leaves in response to larval feeding by Pandemis heparana Denis and Schiffermüller (Giacomuzzi 2010; Giacomuzzi et al. 2013, 2016). Among the many compounds emitted by apple leaves, six were considered unique and only released in response to herbivory. In total, 14 compounds, including two benzenoids, phenylacetonitrile, and 2-phenylethanol, elicited antennal responses from male and female moths (Giacomuzzi et al. 2016). Subsequent field trials revealed that none of the individual apple-leaf volatiles was attractive to a mixed population of $P$. heparana and $P$. cerasana (Hübner) (Giacomuzzi et al. 2016). Yet, when phenylacetonitrile and 2-phenylethanol were individually combined with acetic acid, each binary blend caught a similar number of moths and each caught significantly more moths than their individual components (Giacomuzzi et al. 2016). In a similar study focussed on the North American tortricid species, Spilonota ocellana (Denis and Schiffermüller) and C. rosaceana, El-Sayed et al. (2016) recorded incidental catches of two nontarget species, $P$. limitata and $P$. pyrusana, using binary blends of acetic acid and these same aromatic benzenoids. Collectively, these studies suggest it may be feasible to develop kairomone-based lures for trapping female $P$. limitata that could be beneficial for organic apple producers.

The overall objective of the present study was to gather information to facilitate the development of kairomone-based trapping of female $P$. limitata. Specific objectives of the current study are: (1) to confirm the relative attraction of $P$. limitata by acetic acid, phenylacetonitrile, 2-phenylethanol, and various combinations, (2) to test some prototype commercial dispensers, (3) to measure the attraction of these kairomones relative to a sex pheromone, and (4) to examine the impact of combining sex pheromone and kairomone lures in the same trap on relative catches of male and female $P$. limitata.

\section{Materials and methods}

All trapping experiments were conducted in a 30-ha commercial organic apple orchard several kilometres south of Cawston (latitude $49.0142^{\circ} \mathrm{N}$, $119.6974^{\circ} \mathrm{W}$, elevation $400 \mathrm{~m}$ ) in the Similkameen Valley, British Columbia, Canada. This orchard contained several varietal plantings or orchard blocks (Ambrosia, Gala, Granny Smith, and Spartan), of dwarfing, high-density superspindle trees with an average height of 3-4 m and 12005444 apple trees/ha.

Glacial acetic acid, phenylacetonitrile, 2-phenylethanol, and dichloromethane solvent were purchased in $99 \%$ purity from SigmaAldrich (St. Louis, Missouri, United States of America). Two P. limitata pheromone components (Roelofs et al. 1976), Z11-tetradecenyl acetate (Z11-14:OAc) and Z-9-tetradecenyl alcohol (Z9-14:OH) were purchased in $99 \%$ isomeric purity from Pherobank (Wageningen, The Netherlands). Acetic acid was stored at ambient laboratory temperature $\left(20^{\circ} \mathrm{C}\right)$ while all other compounds were stored at $-20^{\circ} \mathrm{C}$ until used.

In most experiments acetic acid was dispensed from an 8-mL polypropylene vial (Nalg-Nunc International, Rochester, New York, United States of America). Each vial contained $3 \mathrm{~mL}$ of glacial acetic acid applied to two cotton balls. Volatilised acetic acid was emitted through a 3-mm-diameter hole drilled in the lid of each vial. This acetic acid release device, hereafter referred to as our standard acetic-acid co-lure, was modified after Landolt et al. (2007) and used by El-Sayed et al. (2016). Red natural rubber septa (VWR International, 
Mississauga, Ontario, Canada) were used to release phenylacetonitrile, 2-phenylethanol, and pheromone alone and in combination in various experiments (Judd et al. 2017). All rubber septa were extracted with dichloromethane for 24 hours and air dried in a fume hood overnight before use. To construct composite binary or ternary lures containing acetic acid + phenylacetonitrile, acetic acid +2phenylethanol, acetic acid + phenylacetonitrile + 2phenylethanol, or acetic acid + 2-phenylethanol + sex pheromone, we drilled one or two additional holes ( $5 \mathrm{~mm}$ diameter) in the lid of our standard acetic-acid co-lure into which we inserted the narrow end of a rubber septum. Phenylacetonitrile, 2-phenylethanol, and sex pheromone were dissolved in dichloromethane and loaded into and volatilised from the large wells of these rubber septa. Proprietary polymeric cup membrane dispensers (Trécé Incorporated, Adair, Oklahoma, United States of America) having a $1.8-\mathrm{cm}$ diameter membrane release surface were used in two experiments to release acetic acid (TRE-1468), phenylacetonitrile (TRE-1381), 2phenylethanol (TRE-1256), and phenylacetonitrile + 2-phenylethanol (TRE-1379). The physical properties and loadings of these prototype commercial membrane dispensers are proprietary.

Pherocon ${ }^{\circledR}$ VI style, white plastic delta traps with polybutene sticky liners (Trécé Incorporated) were used in all experiments. Individual experiments were conducted in separate varietal blocks separated by over $50 \mathrm{~m}$ within the 30 -ha orchard. All traps were hung from wires within apple trees at $\sim 1.7 \mathrm{~m}$ above ground with $20 \mathrm{~m}$ between the treatment traps within each replicate $(=$ statistical block) and all statistical blocks of traps were separated by at least $30 \mathrm{~m}$. Treatment traps were assigned randomly to positions within each statistical block using a random number table. All traps were at least $30 \mathrm{~m}$ from the border of any orchard varietal block. Sticky-trap liners were replaced at least weekly and returned to the laboratory where moths were counted and sexed.

Experiment 1 was conducted to measure the relative attraction of acetic acid, phenylacetonitrile, and 2-phenylethanol alone and in binary and ternary combination. In total, eight treatments were included in this experiment: blank control, acetic acid, phenylacetonitrile, 2-phenylethanol, phenylacetonitrile +2-phenylethanol, acetic acid+ phenylacetonitrile, acetic acid + 2-phenylethanol, and acetic acid + phenylacetonitrile + 2-phenylethanol.
Traps with the blank, phenylacetonitrile, 2-phenylethanol, and phenylacetonitrile + 2-phenylethanol treatments all contained an empty $8 \mathrm{~mL}$ vial + a blank rubber septum or one containing $10 \mathrm{mg}$ of the corresponding benzenoid compounds, respectively. All traps baited with treatments that included acetic acid contained our standard acetic-acid co-lure. All of these composite lures were attached at the centre and on the side, inner surface, of a delta trap using a 2.5-cm length of Velcro ${ }^{\circledR}$ industrial sticky-back tape (Canadian Tire, Penticton, British Columbia, Canada). This experiment had five replicates and was conducted from 8-22 August 2016.

Experiment 2 was conducted to measure and compare the relative attraction of acetic acid+ phenylacetonitrile, acetic acid + 2-phenylethanol, and acetic acid + phenylacetonitrile +2 -phenylethanol when the aromatic compounds were released from rubber septa or commercial prototype membrane dispensers (Trécé Incorporated). These rubber septa and membrane dispensers provide markedly different chemical release rates (Knight et al. 2017). For example, red rubber septa loaded with $10 \mathrm{mg}$ of 2-phenylethanol and the TRE-1256 membrane lure released 2-phenylethanol at rates of $0.62 \pm 0.01$ and $1.01 \pm 0.03 \mathrm{mg} / \mathrm{day}$, when held at $25^{\circ} \mathrm{C}$, respectively (Knight et al. 2017). There were six treatment combinations (three aromatic blends $\times$ two release devices) in this experiment: (1) phenylacetonitrile (TRE-1381), (2) 2phenylethanol (TRE-1256), (3) phenylacetonitrile + 2-phenylethanol (TRE-1379), (4) one septum loaded with $10 \mathrm{mg}$ of phenylacetonitrile, (5) one septum loaded with $10 \mathrm{mg}$ of 2-phenylethanol, and (6) one septum loaded with $10 \mathrm{mg}$ of phenylacetonitrile and one septum loaded with $10 \mathrm{mg}$ of 2phenylethanol. All lure treatments contained our standard acetic-acid co-lure that was combined with a septum as necessary and attached to delta traps with Velcro as described before. All membrane lures were pinned inside each delta trap at the centre apex. This experiment was conducted with none replicates from 10-24 August 2016.

Experiment 3 was conducted to measure the relative attraction of acetic acid + 2-phenylethanol lures when 2-phenylethanol was released from either rubber septa or membrane dispensers (see experiment 2) in combination with acetic acid released from either of two co-lures having markedly different release rates. Laboratory gravimetric analyses at $25^{\circ} \mathrm{C}$ indicates that our standard acetic-acid co-lure 
and a TRE-1468 acetic-acid-membrane co-lure release acetic acid at rates of $62.65 \pm 2.39$ and $27.77 \pm 0.48 \mathrm{mg} /$ day, respectively (Knight et al. 2017). There were four treatment combinations (two acetic acid sources $\times$ two 2-phenylethanol release devices) in this experiment: (1) a standard acetic-acid co-lure + septum loaded with $10 \mathrm{mg}$ of 2-phenylethanol; (2) a standard acetic-acid co-lure + membrane 2-phenylethanol lure (TRE1256); (3) a membrane acetic-acid co-lure (TRE-1468) + septum loaded with $10 \mathrm{mg}$ of 2phenylethanol; and (4) a membrane acetic-acid colure (TRE-1468) + membrane 2-phenylethanol lure (TRE-1256). All standard acetic-acid co-lures were combined with a septum as necessary and attached to delta traps with Velcro as described before. All membrane lures were pinned inside each delta trap at the centre apex. This experiment was conducted with six replicates from 12-24 August 2016.

Experiment 4 was conducted to measure the attraction of an acetic acid +2-phenylethanol lure relative to a sex pheromone lure, and to test the hypothesis that combining this kairomone with a sex pheromone might increase catches of male $P$. limitata. We compared three treatment lures in this experiment: (1) a 1-mg sex-pheromone septum lure, (2) a standard acetic-acid co-lure $+10 \mathrm{mg} 2$ phenylethanol septum lure, and (3) a standard acetic-acid co-lure $+10 \mathrm{mg}$ 2-phenylethanol septum lure $+1 \mathrm{mg}$ sex pheromone septum lure. The latter treatment tested the hypothesis that combining these semiochemicals in the same trap could lead to a more attractive male lure. Sex pheromone and 2-phenylethanol were loaded on separate septa to avoid any chemical interaction on the release substrate. The sex pheromone lure contained $1 \mathrm{mg}$ of a 94:6 blend of Z11-14:OAc and Z9-14:OH (Roelofs et al. 1976). The sex-pheromone septum was pinned to the 2-phenylethanol septum. This experiment had seven replicates and was conducted from 17-31 August 2016.

All insect count data were tested for normality (Kolmogorov-Smirnov test) and equality of variances (Levine's Median test) to ensure they met the assumptions of an analysis of variance (ANOVA). Any non-normal data sets were normalised and variances stabilised using a $\sqrt{ }(x+0.5)$ transformation (Zar 1984). Mean treatment catches were analysed post hoc using Tukey's honest significant difference multiplecomparison test following significant ANOVA.
In experiments $1-3$ we performed preliminary ANOVA analyses to test for various interactions and if none were present we analysed experiments as randomised complete block designs using two-way ANOVA with no interaction (Zar 1984). All statistical analyses were performed with experimental error rates set at $\alpha=0.05$ using SigmaPlot ${ }^{\circledR} 12.5$ (SYSTAT Software, San Jose, California, United States of America).

\section{Results}

In experiment 1 the treatment lures had a significant effect $(F(6,52)=48.714, P<0.001)$ on moth catch but the ranking of the seven treatment lures (blank excluded) was independent of moth sex because the sex $\times$ lure interaction was nonsignificant $(F(6,52)=0.288, P=0.492)$. Therefore, we pooled male $(52.4 \%)$ and female $(47.6 \%)$ catches and compared treatment lures using total moth catch $(F(6,24)=55.721, P<0.001)$ (Fig. 1). Neither of the individual benzenoid compounds, nor a binary combination, caught many $P$. limitata (Fig. 1). Moth catches with acetic acid were small but greater than zero (one-tailed test, $t=2.059$, $\mathrm{df}=4, P=0.06$ ), suggesting acetic acid is a weak attractant. More importantly, moth catches increased significantly when acetic acid was added as a co-lure to 2-phenylethanol, phenylacetonitrile, and 2phenylethanol + phenylacetonitrile combined (Fig. 1). Traps baited with acetic acid+2-phenylethanol caught significantly more moths than traps baited with acetic acid+phenylacetonitrile, but catches with acetic acid+2-phenylethanol were not significantly different than those in traps baited with the ternary blend including phenylacetonitrile (Fig. 1).

In experiment 2, total moth catch was significantly affected by the aromatic volatile treatment $(F(2,48)=11.862, P<0.001)$ and the type of device used to release it $(F(1,48)=36.994$, $P<0.001)$. Because there was no significant interaction of these factors $(F(2,48)=0.143$, $P=0.868$ ), we compared the six combination treatment lures and found significant differences for male $(F(5,40)=17.114, \quad P<0.001)$, female $(F(5,40)=20.643, P<0.001)$, and total moth catch $(F(5,40)=22.249, \quad P<0.001)$ using randomised block ANOVAs (Table 1). In general, membrane dispensers caught more moths than septum dispensers, and acetic acid +2-phenylethanol, and acetic acid +2 -phenylethanol + phenylacetonitrile 
Fig. 1. Mean ( \pm standard error (SE)) total number of Pandemis limitata moths caught during experiment 1 (8-22 August 2016) in sticky white delta traps baited with red rubber septa loaded with $10 \mathrm{mg}$ of phenylacetonitrile (PAN) or 2-phenylethanol (PET) alone, and in binary or ternary combination with an acetic-acid (AA) co-lure ( $3 \mathrm{~mL} \mathrm{AA} / 3 \mathrm{~mm}$ open $8-\mathrm{mL}$ vial) relative to blank traps. Bars followed by a common letter indicate mean total catches are not significantly different (Tukey's honest significant difference test, $\alpha=0.05$ ) following significant analysis of variance $(P<0.05)$. Blank traps not included in statistical analysis.

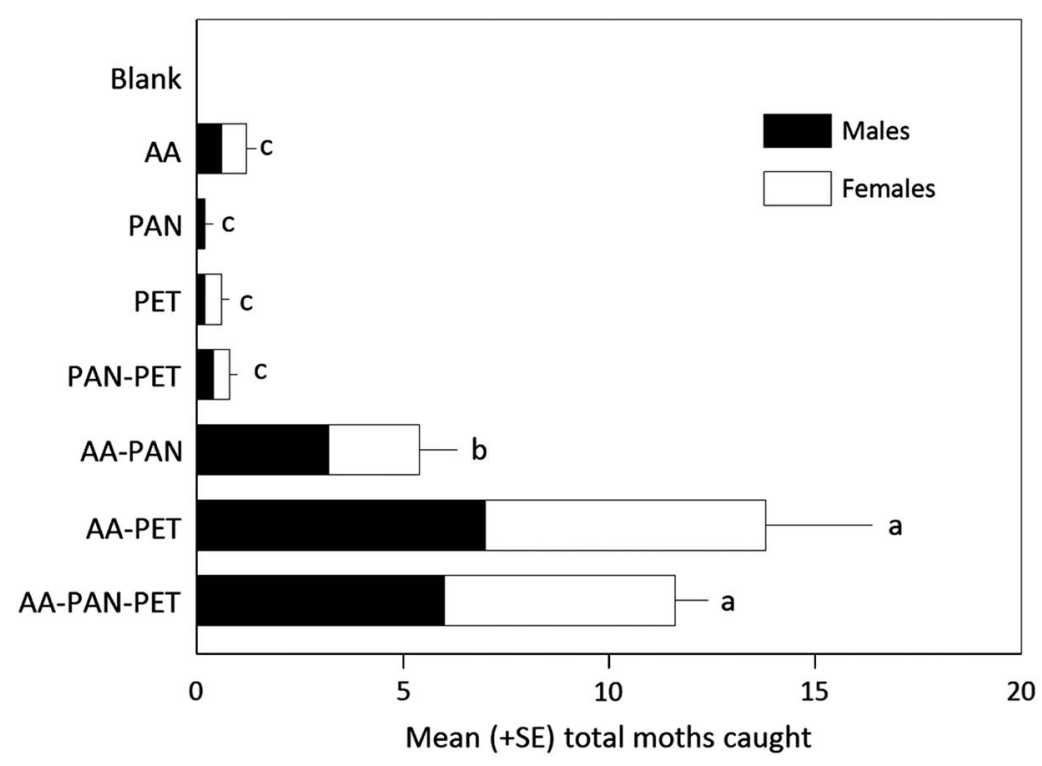

Table 1. Catches of Pandemis limitata moths during experiment 2 (10-24 August 2016) in sticky white delta traps baited with the aromatic compounds phenylacetonitrile (PAN) or 2-phenylethanol (PET) when released from red rubber septa or membrane dispensers in combination with acetic-acid (AA) co-lures ( $3 \mathrm{~mL} \mathrm{AA} / 3 \mathrm{~mm}$ open $8-\mathrm{mL}$ vial).

\begin{tabular}{llccc}
\hline & & \multicolumn{2}{c}{ Mean \pm number of moths caught/experiment } \\
\cline { 3 - 5 } Aromatic dispenser type & Aromatic compounds* & Males & Females & Total \\
\hline Red rubber septum & PAN & $2.6 \pm 0.6 \mathrm{~b}$ & $2.3 \pm 0.6 \mathrm{c}$ & $4.9 \pm 0.8 \mathrm{c}$ \\
& PET & $6.9 \pm 1.4 \mathrm{~b}$ & $7.3 \pm 1.4 \mathrm{~b}$ & $14.9 \pm 2.1 \mathrm{~b}$ \\
& PAN-PET & $4.7 \pm 0.9 \mathrm{~b}$ & $4.8 \pm 0.9 \mathrm{bc}$ & $9.9 \pm 1.3 \mathrm{bc}$ \\
Membrane & PAN & $7.6 \pm 1.8 \mathrm{~b}$ & $7.6 \pm 1.2 \mathrm{~b}$ & $15.3 \pm 2.8 \mathrm{~b}$ \\
& PET & $14.4 \pm 2.2 \mathrm{a}$ & $12.4 \pm 2.3 \mathrm{a}$ & $26.9 \pm 4.2 \mathrm{a}$ \\
& PAN-PET & $11.0 \pm 1.9 \mathrm{a}$ & $10.0 \pm 1.7 \mathrm{a}$ & $21.1 \pm 3.4 \mathrm{a}$ \\
\hline
\end{tabular}

* Each red rubber septum was loaded with $10 \mathrm{mg}$ of each compound. Trécé Incorporated membrane dispensers are loaded with proprietary amounts of PAN (TRE-1381), PET (TRE-1256), and PAN-PET (TRE-1379).

'Means within a column followed by the same letter are not significantly different (Tukey's honest significant difference test, $\alpha=0.05)$ following significant ANOVA $(P<0.05)$.

lures caught similar numbers of moths, but significantly more moths than the acetic acid+ phenylacetonitrile lure (Table 1).

In experiment 3, the amount of acetic acid released by two different co-lures had no significant effect on male $(F(1,15)=0.195, \quad P=0.762)$, female $(F(1,15)=0.421, P=0.74)$, or total moth catch
$(F(1,15)=0.396, \quad P=0.758) \quad$ when combined with the two different 2-phenylethanol dispensers (Table 2). The type of 2-phenylethanol dispenser also had no significant effect on male $(F(1,15)=0.781$, $P=0.421)$, female $(F(1,15)=0.714, P=0.438)$, or total moth catch $(F(1,15)=0.936, P=0.371)$ in experiment 3 (Table 2). 
Table 2. Influence of different acetic-acid co-lures on catches of Pandemis limitata moths during experiment 3 (12-24 August 2016) in sticky white delta traps baited with different 2-phenylethanol dispensers.

\begin{tabular}{lllll}
\hline & & \multicolumn{3}{c}{ Mean \pm number of moths caught/experiment } \\
\cline { 3 - 4 } Acetic acid source* & 2-phenylethanol source & Fales & Females & Total \\
\hline 3-mm open vial & Red rubber septum & $6.7 \pm 1.3 \mathrm{a}$ & $6.8 \pm 1.1 \mathrm{a}$ & $13.5 \pm 1.8 \mathrm{a}$ \\
& TRE-1256 membrane & $8.7 \pm 2.1 \mathrm{a}$ & $7.2 \pm 1.5 \mathrm{a}$ & $15.8 \pm 2.3 \mathrm{a}$ \\
TRE-1468 membrane & Red rubber septum & $6.7 \pm 1.1 \mathrm{a}$ & $5.5 \pm 1.2 \mathrm{a}$ & $12.2 \pm 2.9 \mathrm{a}$ \\
& TRE-1256 membrane & $7.3 \pm 2.1 \mathrm{a}$ & $7.3 \pm 1.7 \mathrm{a}$ & $14.7 \pm 2.3 \mathrm{a}$ \\
\hline
\end{tabular}

* Acetic acid emission at $25^{\circ} \mathrm{C}$ based on weight loss is $62.65 \pm 2.39 \mathrm{mg} / \mathrm{day}$ from vials and $27.77 \pm 0.48 \mathrm{mg} / \mathrm{day}$ from TRE-1468 membrane (Knight et al. 2017).

${ }^{\dagger}$ 2-phenylethanol emission at $25^{\circ} \mathrm{C}$ based on weight loss is $0.62 \pm 0.01 \mathrm{mg} / \mathrm{day}$ for a septum and $1.01 \pm 0.03 \mathrm{mg} / \mathrm{day}$ from TREC-1256 membrane (Knight et al. 2017).

${ }^{\ddagger}$ Means within a column followed by the same letter are not significantly different by ANOVA $(P>0.05)$.

Table 3. Comparative catches of Pandemis limitata moths during experiment 4 (17-31 August 2016) in sticky white delta traps baited with sex pheromone and kairomone alone and combined.

\begin{tabular}{lccccc}
\hline & & & \multicolumn{2}{c}{ Mean \pm number of moths caught/experiment ${ }^{\dagger}$} \\
\cline { 5 - 6 } Pheromone lures* & Kairomone & & Males & Females & Total \\
\hline+ & - & & $9.3 \pm 1.1 \mathrm{a}$ & - & $9.3 \pm 1.1 \mathrm{a}$ \\
+ & + & & $4.6 \pm 0.8 \mathrm{~b}$ & $2.3 \pm 0.4 \mathrm{~b}$ & $6.9 \pm 1.2 \mathrm{ab}$ \\
- & + & & $1.1 \pm 0.5 \mathrm{c}$ & $4.9 \pm 0.9 \mathrm{a}$ & $6.0 \pm 1.4 \mathrm{~b}$ \\
\hline
\end{tabular}

* Sex pheromone lures contained $1 \mathrm{mg}$ of a 94:6 blend of Z11-14:OAc and Z9-14:OH (Roelofs et al. 1976). Kairomone lures contained $10 \mathrm{mg}$ of 2-phenylthanol on a red septum and $3 \mathrm{~mL}$ of acetic acid in a 3-mm open 8-mL polypropylene vial. Pheromone and 2-phenylethanol were on separate septa in combined treatment $(++)$.

${ }^{\dagger}$ Means within a column followed by the same letter are not significantly different by Tukey’s honest significant difference test $(\alpha=0.05)$ following a significant ANOVA $(P<0.05)$.

In experiment 4 , catches of male $P$. limitata in traps baited with a sex pheromone lure were eight times greater $(F(2,12)=44.8, P<0.001)$ than male catches in traps baited with the acetic acid +2 phenylethanol kairomone lure (Table 3). Traps baited with a sex pheromone and kairomone combined caught 0.5 times fewer male moths than traps baited with sex pheromone alone, but four times more male $P$. limitata than the acetic acid+2-phenylethanol kairomone lure alone. Significantly $(F(1,6)=6.568$, $P=0.025$ ) fewer females (53\%) were caught by the kairomone lure when a sex pheromone lure was placed in the same trap (Table 3). Total moth catches with sex pheromone were significantly $(F(2,12)=4.463, \quad P=0.036)$ greater than total catches with kairomone or kairomone plus sex pheromone (Table 3).

\section{Discussion}

Our studies have confirmed that a binary lure releasing acetic acid and 2-phenylethanol attracts both male and female $P$. limitata and is a more attractive lure than either component alone. The experiment with rubber septa lures clearly showed that 2-phenylethanol alone is an ineffective attractant of $P$. limitata, whereas acetic acid appeared weakly attractive as it is for several tortricid species (Knight et al. 2014). These results are consistent with European studies showing that 2-phenylethanol was not attractive to Pandemis species when used alone (Giacomuzzi et al. 2016). However, unlike Pandemis species in the European study (Giacomuzzi et al. 2016), P. limitata moths were caught significantly more often with acetic acid +2-phenylethanol than they were with acetic acid + phenylacetonitrile. Given the relatedness of these Nearctic Pandemis species (Dombroskie and Sperling 2012) it seems likely that the differences among species, in terms of catches with these two caterpillar-induced benzenoid compounds, probably has more to do with experimental details than differences in olfactory preference. Mean moth catches in the European study were several times 
lower than ours, and the authors reported using fewer replicates, therefore, population density and dispersion differences may have led to more variation and a lack of statistical separation among lure treatments (Giacomuzzi et al. 2016).

Pandemis limitata, like C. rosaceana (Knight et al. 2017), was caught significantly more often in traps baited with acetic acid + 2-phenylethanol than in traps baited with acetic acid + phenylacetonitrile, whereas catches of another sympatric leafroller, S. ocellana, were greatest with acetic acid+ phenylacetonitrile (Judd et al. 2017). These results prompted us to question whether the species differences in adult response are related to the relative amounts of these two benzenoids in the apple-leaf volatiles that the caterpillar of each species induces. Our review of the relevant literature (El-Sayed et al. 2016; Giacomuzzi et al. 2016, 2017b) suggests that the headspace volatiles described for the various caterpillar species do little to explain these results. 2-phenylethanol is no more prevalent in volatiles induced by species that respond strongly to it (Pandemis and C. rosaceana) than it is in the volatiles induced by S. ocellana. The ratio of 2-phenylethanol: phenylacetonitrile in headspace volatiles induced by $P$. limitata is unknown, but the ratios induced in response to feeding by $P$. heparana (Giacomuzzi et al. 2016), P. pyrusana (Giacomuzzi et al. 2017b), and S. ocellana (El-Sayed et al. 2016) are $0.15,0.29$, and 1.04 , respectively. These ratios do not explain the differences in the catches of these various tortricid species with acetic acid+ 2-phenylethanol or phenylacetonitrile. Although the apple-leaf volatiles induced by these various tortricid species act as conspecific attractants (ElSayed et al. 2016) they also appear to act as broad tortricid attractants. Several papers have now shown that benzenoids are common herbivoreinduced plant volatiles that attract adult tortricids when presented in combination with acetic acid. The behavioural differences among adults of each species do not appear related to the caterpillarinduced specific ratios. This suggests that these compounds or their blends are not species-specific and a herbivore-induced plant volatile blend induced by one caterpillar might attract heterospecific adults. The overall ecological significance of these adult responses is currently unknown, but purported to be related to host-plant finding (ElSayed et al. 2016) or attraction to food-based cues associated with microbial growth or host suitability (Giacomuzzi et al. 2017b).

Given the general attraction of several tortricid species to acetic acid+2-phenylethanol it seems premature to assign any species-specific behavioural significance to catches of $P$. limitata with this lure. The behavioural "motivation" of captured insects is almost always unknown and these two compounds are found together in other natural contexts. While it is true both acetic acid and 2-phenylethanol are present in volatiles from caterpillar-infested apple leaves (El-Sayed et al. 2016; Giacomuzzi et al. 2016) they are also emitted by undamaged apple leaves (Giacomuzzi et al. 2017a, 2017b). Furthermore, 2-phenylethanol is found in fermenting sweet baits, floral odours, and fruit aromas (El-Sayed et al. 2005; Knudsen et al. 2006; Negre-Zakharov et al. 2009). A wide range of moths are attracted to these odours (El-Sayed 2016). More precise work on feeding and hostselection behaviour in P. limitata will be needed to fully understand the behavioural significance of its response to acetic acid and 2-phenylethanol.

Larval host plants can influence mating behaviour in many Lepidoptera (Landolt and Phillips 1997) and there is good evidence that host-plant volatiles increase the sex pheromone responses of male Lepidoptera including tortricids (Dickens et al. 1993; Landolt and Phillips 1997; Reddy and Guerrero 2004; Yang et al. 2004; Schmidt-Büsser et al. 2009; Varela et al. 2011; von Arx et al. 2012). El-Sayed et al. (2016) suggested that combining caterpillar-induced benzenoid-based kairomones with sex pheromone might increase catches of male tortricid moths. However, we found that adding acetic acid + 2-phenylathanol to the sex pheromone of $P$. limitata significantly reduced male moth catch. Likewise, both 2-phenylethanol and phenylacetonitrile without acetic acid (Knight et al. 2017) and phenylacetonitrile with acetic acid (Judd et al. 2017), significantly reduced catches of C. rosaceana and S. ocellana in pheromone-baited traps, respectively. Hatano et al. (2015) demonstrated that some herbivore-induced plant volatiles can suppress olfactory neuronal signalling pathways and inhibit sexual behaviours in both male and female Spodoptera littoralis Boisduval (Lepidoptera: Noctuidae). Our negative result combining the caterpillar-induced volatiles acetic acid and 2-phenylethanol with sex pheromone supports a large body of literature suggesting 
herbivore-induced volatiles identify plants of poor quality that should be detected and avoided (De-Moraes et al. 2001). Experiments that examine mating behaviour of male and female Pandemis leafrollers on conspecific-infested and clean plants are needed to critically examine the role of benzenoids in finding mates or host plants (El-Sayed et al. 2016).

Combining 2-phenylethanol and sex pheromone not only reduced catches of male $P$. limitata, but somewhat surprisingly, it also reduced catches of females. Female $P$. limitata are capable of detecting their own pheromone and exposure to high doses, as might be experienced near pheromone dispensers, causes females to move more frequently (DeLury et al. 2005). It seems possible that the detection of sex pheromone near sources of caterpillar-induced kairomones might cause female moths to be repelled and avoid trap entry. Auto-detection of sex pheromone by female moths and subsequent changes in flight and dispersal behaviour has been reported in other tortricid species (Palaniswamy and Seabrook 1978; Barnes et al. 1992; Weissling and Knight 1996). However, not all tortricids respond this way because catches of female $S$. ocellana were not reduced when phenylacetonitrile and sex pheromone were combined in a single trap or dispenser (Judd et al. 2017). Given these species differences it will be necessary to examine the semiochemical interactions for each target species separately before deciding whether combining semiochemicals is worthwhile.

Development of multispecies kairomone-based trapping to manage a suite of sympatric tortricid moths is a logical extension of the approach being used to develop mating disruption for leafroller complexes (Judd and Gardiner 2004, 2008). With $S$. ocellana, a ternary blend of acetic acid + phenylacetonitrile + 2-phenylethanol caught as many female moths as did the optimal binary blend, acetic acid + phenylacetonitrile (Judd et al. 2017). Similarly, this same ternary blend caught as many female $P$. limitata as did its optimal binary blend, acetic acid+2-phenylethanol. Therefore, using this single ternary blend it should be possible to simultaneously trap a suite of tortricid moths. This lure may allow development of multispecies mass trapping as a supplement to multispecies pheromone disruption or as a stand-alone organic control. This emergent technology will require development of long-lasting commercial release devices, certified organic trapping systems, and a full understanding of the various semiochemical interactions of the important and unique species complex within each growing region.

\section{Acknowledgements}

The authors thank Mark Gardiner and Kandace Zurowski-Tiffin for their technical assistance and most especially their preparation of lures. The authors thank Godfrey Sellmer for allowing us to conduct research trials in his orchard. The authors also thank Bill Lingren, Trécé Incorporated (Adair, Oklahoma, United States of America) for donating some of the dispensers used in our studies. This project was supported with partial funding from the Washington Tree Fruit Research Commission (Wenatchee, Washington, United States of America).

\section{References}

Barnes, M.M., Millar, J.G., Kirsch, P.A., and Hawks, D.C. 1992. Codling moth (Lepidoptera: Tortricidae) control by dissemination of synthetic female sex pheromone. Journal of Economic Entomology, 85: 1274-1277.

Beers, E.H., Brunner, J.F., Willett, M.J., and Warner, G.W. 1993. Orchard pest management: a resource book for the Pacific Northwest. Good Fruit Grower, Yakima, Washington, United States of America.

Brunner, J.F. and Beers, E.H. 1990. Pandemis and obliquebanded leafrollers. Washington State University Extension Bulletin, 1582. Washington State University, Wenatchee, Washington, United States of America.

Cardé, R.T. and Minks, A.K. 1995. Control of moths by mating disruption: successes and constraints. Annual Review of Entomology, 40: 559-585.

DeLury, N.C., Judd, G.J.R., and Gardiner, M.G.T. 2005. Antennal detection of sex pheromone by female Pandemis limitata (Robinson) (Lepidoptera: Tortricidae) and its impact on their calling behaviour. Journal of the Entomological Society of British Columbia, 102: 3-11.

De-Moraes, C.M., Mescher, M.C., and Tumlinson, J.H. 2001. Caterpillar-induced nocturnal plant volatiles repel conspecific females. Nature, 410: 577-580.

Dickens, J.C., Smith, J.W., and Light, D.M. 1993. Green leaf volatiles enhance sex attractant pheromone of the tobacco budworm, Heliothis virescens (Lep.: Noctuidae). Chemoecology, 4: 175-177.

Dombroskie, J.J. and Sperling, F.A.H. 2012. Phylogeny of Nearctic Pandemis (Lepidoptera: Tortricidae) with focus on species boundaries in the $P$. limitata group. Annals of the Entomological Society of America, 105: 768-780. 
Edwards, L. 1998. Organic tree fruit management. Certified Organic Associations of British Columbia, Keremeos, British Columbia, Canada.

El-Sayed, A.M. 2016. The pherobase: database of pheromones and semiochemicals [online]. Available from www.pherobase.com [accessed 10 November 2016].

El-Sayed, A.M., Heppelthwaite, V.J., Manning, L.M., Gibb, A.R., and Suckling, D.M. 2005. Volatile constituents of fermented sugar baits and their attraction to lepidopteran species. Journal of Agricultural and Food Chemistry, 53: 953-958.

El-Sayed, A.M., Knight, A.L., Byers, J.A., Judd, G.J. R., and Suckling, D.M. 2016. Caterpillar-induced plant volatiles attract conspecific adults in nature. Scientific Reports, 6: 37555. https://doi.org/10.1038/ srep37555.

Giacomuzzi, V. 2010. Changes in apple plant volatiles in response to feeding damage of Pandemis heparana. B.Sc. thesis, SRC0004562. BozenBolzano University, Bolzano, Italy.

Giacomuzzi, V., Abraham, J., and Angeli, S. 2013. Feeding damage of Pandemis heparana induces the release of specific volatile compounds from apple plants. Proceedings of a Conference on International Research in Food Security, 17-19 September 2013. University of Hohenheim. Available from www. tropentag.de/2013/abstracts/full/312.pdf [accessed 6 July 2017].

Giacomuzzi, V., Cappellin, L., Khomenko, I., Biasioli, F., Schutz, S., Tasin, M., et al. 2016. Emission volatile compounds from apple plants infested with Pandemis heparana larvae, antennal response of conspecific adults, and preliminary field trial. Journal of Chemical Ecology, 42: 1265-1280.

Giacomuzzi, V., Cappellin, L., Nones, S., Khomenko, I., Knight, A., Biasioli, F., and Angeli, S. 2017a. Circadian rhythms of volatile emission from apple and grape foliage. Phytochemistry, 138: 104-115.

Giacomuzzi, V., Matthias, J., Basoalto, E., and Knight, A. L. 2017b. Survey of conspecific herbivore-induced volatiles from apple as possible attractants for Pandemis pyrusana (Lepidoptera: Tortricidae). Pest Management Science, 73: 1837-1845.

Hári, K., Pénzes, B., Jósvai, J., Holb, I., Szarukán, I., Szólláth, I., et al. 2011. Performance of traps baited with pear ester-based lures vs. pheromone baited ones for monitoring codling moth Cydia pomonella L. in Hungary. Acta Phytopathologica et Entomologica Hungarica, 46: 225-234.

Hatano, E., Saveer, A.M., Borrero-Echeverry, F., Strauch, M., Zakir, A., Bengtsson, M., et al. 2015. A herbivore-induced plant volatile interferes with host plant and mate location in moths through suppression of olfactory signalling pathways. BMC Biology, 13: 275. https://doi.org/10.1186/s12915-015-0188-3.

Judd, G.J.R. and Gardiner, M.G.T. 2004. Simultaneous disruption of pheromone communication and mating in Cydia pomonella, Choristoneura rosaceana and Pandemis limitata (Lepidoptera: Tortricidae) using isomate-CM/LR in apple orchards. Journal of the Entomological Society of British Columbia, 101: 3-14.
Judd, G.J.R. and Gardiner, M.G.T. 2008. Efficacy of isomate-CM/LR for management of leafrollers by mating disruption in organic apple orchards of western Canada. Journal of the Entomological Society of British Columbia, 105: 45-60.

Judd, G.J.R., Knight, A.L., and El-Sayed, A.M. 2017. Development of kairomone-based lures and traps targeting female Spilonota ocellana (Lepidoptera: Tortricidae) in apple orchards treated with sex pheromones. The Canadian Entomologist, 149: 662-676.

Knight, A.L. 2010. Improved monitoring of female codling moth (Lepidoptera: Tortricidae) with pear ester plus acetic acid in sex pheromonetreated orchards. Environmental Entomology, 39: 1283-1290.

Knight, A.L., El-Sayed, A.M., Judd, G.J.R., and Basoalto, E. 2017. Development of 2-phenylethanol plus acetic acid lures to monitor obliquebanded leafroller (Lepidoptera: Tortricidae) under mating disruption. Journal of Applied Entomology, https://doi.org/ 10.1111/jen.12393.

Knight, A.L., Hilton, R., Basoalto, E., and Stelinski, L.L. 2014. Use of glacial acetic acid to enhance bisexual monitoring of tortricid pests with kairomone lures in pome fruits. Environmental Entomology, 43: 1628-1640.

Knight, A.L., Thomson, D.R., and Cockfield, S.D. 1998. Developing mating disruption of obliquebanded leafroller (Lepidoptera: Tortricidae) in Washington State. Environmental Entomology, 27: 1080-1088.

Knight, A.L. and Turner, J.E. 1999. Mating disruption of Pandemis spp. (Lepidoptera: Tortricidae). Environmental Entomology, 28: 81-87.

Knudsen, J.T., Eriksson, R., Gershenzon, J., and Ståhl, B. 2006. Diversity and distribution of floral scent. Botanical Review, 72: 1-120.

Landolt, P.J. and Phillips, T.W. 1997. Host plant influences on sex pheromone behavior of phytophagous insects. Annual Review of Entomology, 42: 371-391.

Landolt, P.J., Suckling, D.M., and Judd, G.J.R. 2007. Positive interaction of a feeding attractant and a host kairomone for trapping the codling moth, Cydia pomonella (L.). Journal of Chemical Ecology, 33: 2236-2244.

Madsen, H.F. and Procter, P.J. 1985. Insects and mites of tree fruits in British Columbia. Publication 82-6, British Columbia Ministry of Agriculture and Food, Victoria, British Columbia, Canada.

Negre-Zakharov, F., Long, M.C., and Dudareva, N. 2009. Floral scents and fruit aromas inspired by nature. In Plant-derived natural products: synthesis, function and application, part 3. Edited by A.E. Osbourn and V. Lanzott. Springer, New York, New York, United States of America. Pp. 405-431.

Palaniswamy, P. and Seabrook, W.D. 1978. Behavioural responses of the female eastern spruce budworm Choristoneura fumiferana (Lepidoptera: Tortricidae) to the sex pheromone of her own species. Journal of Chemical Ecology, 4: 649-655. 
Reddy, G.V.P. and Guerrero, G. 2004. Interactions of insect pheromones and plant semiochemicals. Trends in Plant Science, 9: 253-261.

Roelofs, W., Cardé, A., Hill, A., and Cardé, R. 1976. Sex pheromone of the threelined leafroller, Pandemis limitata. Environmental Entomology, 5: 649-652.

Schmidt-Büsser, D., von Arx, M., and Guerin, P.M. 2009. Host plant volatiles serve to increase the response of male European grape berry moths, Eupoecilia ambiguella, to their sex pheromone. Journal of Comparative Physiology A, 195: 853-864.

Varela, N., Avilla, J., Anton, S., and Gemeno, C. 2011. Synergism of pheromone and host-plant volatile blends in the attraction of Grapholita molesta males. Entomologia Experimentalis et Applicata, 141: 114-122. von Arx, M., Schmidt-Büsser, D., and Guerin, P.M. 2012. Plant volatiles enhance behavioral responses of grapevine moth males, Lobesia botrana to sex pheromone. Journal of Chemical Ecology, 38: 222-225.

Weissling, T.J. and Knight, A.L. 1996. Oviposition and calling behavior of codling moth (Lepidoptera: Tortricidae) in the presence of codlemone. Annals of the Entomological Society of America, 89: 142-147.

Witzgall, P., Kirsch, P., and Cork, A. 2010. Sex pheromones and their impact on pest management. Journal of Chemical Ecology, 36: 80-100.

Yang, Z.H., Bengtsson, M., and Witzgall, P. 2004. Host plant volatiles synergize response to sex pheromone in codling moth, Cydia pomonella. Journal of Chemical Ecology, 30: 619-629.

Zar, J.H. 1984. Biostatistical analysis. Prentice Hall, Englewood Cliffs, New Jersey, United States of America. 